Larkin, Fionnuala ORCID:

https://orcid.org/0000-0003-3838-9165, Guerin, Suzanne, Hobson, Jessica Anne and Gutstein, Steven E. (2015) The Relationship Development Assessment - Research Version: Preliminary validation of a clinical tool and coding schemes to measure parentchild interaction in autism. Clinical Child Psychology and Psychiatry, 20 (2).

Downloaded from: http://ray.yorksj.ac.uk/id/eprint/3885/

The version presented here may differ from the published version or version of record. If you intend to cite from the work you are advised to consult the publisher's version: https://journals.sagepub.com/doi/10.1177/1359104513514065

Research at York St John (RaY) is an institutional repository. It supports the principles of open access by making the research outputs of the University available in digital form. Copyright of the items stored in RaY reside with the authors and/or other copyright owners. Users may access full text items free of charge, and may download a copy for private study or non-commercial research. For further reuse terms, see licence terms governing individual outputs. Institutional Repository Policy Statement

\title{
RaY
}

Research at the University of York St John

For more information please contact RaY at ray@yorks.ac.uk 
Clinical Child Psychology and Psychiatry

\section{The Relationship Development Assessment - Research Version: Preliminary validation of a clinical tool and coding schemes to measure parent-child interaction in autism.}

\begin{tabular}{|c|c|}
\hline Journal: & Clinical Child Psychology and Psychiatry \\
\hline Manuscript ID: & CCPP-13-0026.R2 \\
\hline Manuscript Type: & Original Manuscript \\
\hline Keywords: & $\begin{array}{l}\text { autism, joint attention, intersubjectivity, parent-child interaction, } \\
\text { relatedness }\end{array}$ \\
\hline Abstract: & $\begin{array}{l}\text { The aim of this project was to replicate and extend findings from two } \\
\text { recent studies on parent-child relatedness in autism (Beurkens, Hobson \& } \\
\text { Hobson, 2013; Author reference withheld for blind review) by adapting an } \\
\text { observational assessment and coding schemes of parent-child relatedness } \\
\text { for the clinical context, and examining their validity and reliability. The } \\
\text { coding schemes focussed on three aspects of relatedness: joint attentional } \\
\text { focus (Adamson, Bakeman \& Deckner, 2004), the capacity to co-regulate } \\
\text { an interaction, and the capacity to share emotional } \\
\text { experiences. Participants were } 40 \text { children ( } 20 \text { with autism, } 20 \text { without } \\
\text { autism) aged } 6 \text { - 14, and their parents. Parent-child dyads took part in the } \\
\text { observational assessment and were coded on these } \\
\text { schemes. Comparisons were made with standardised measures of autism } \\
\text { severity (Autism Diagnostic Observation Schedule, ADOS: Lord, Rutter, } \\
\text { DiLavore \& Risi, 2001; Social Responsiveness Scale, SRS: Constantino \& } \\
\text { Gruber, 2005), relationship quality (Parent Child Relationship Inventory, } \\
\text { PCRI: Gerard, 1994), and quality of parent-child interaction (Dyadic Coding } \\
\text { Scales, DCS: Humber \& Moss, } 2005 \text { ). Inter-rater reliability was very good } \\
\text { and, as predicted, codes both diverged from the measure of parent-child } \\
\text { relationship and converged with a separate measure of parent-child } \\
\text { interaction quality,. Detailed profile review revealed nuanced areas of } \\
\text { group and individual differences which may be specific to verbally-able } \\
\text { school-age children. Results support the utility of the Relationship } \\
\text { Development Assessment - Research version for clinical practice. }\end{array}$ \\
\hline
\end{tabular}

\section{SCHOLARONE \\ Manuscripts}




\begin{abstract}
The aim of this project was to replicate and extend findings from two recent studies on parent-child relatedness in autism (Beurkens, Hobson \& Hobson, 2013; Author reference withheld for blind review) by adapting an observational assessment and coding schemes of parent-child relatedness for the clinical context, and examining their validity and reliability. The coding schemes focussed on three aspects of relatedness: joint attentional focus (Adamson, Bakeman \& Deckner, 2004), the capacity to co-regulate an interaction, and the capacity to share emotional experiences. Participants were 40 children ( 20 with autism, 20 without autism) aged $6-14$, and their parents. Parent-child dyads took part in the observational assessment and were coded on these schemes. Comparisons were made with standardised measures of autism severity (Autism Diagnostic Observation Schedule, ADOS: Lord, Rutter, DiLavore \& Risi, 2001; Social Responsiveness Scale, SRS: Constantino \& Gruber, 2005), relationship quality (Parent Child Relationship Inventory, PCRI: Gerard, 1994), and quality of parent-child interaction (Dyadic Coding Scales, DCS: Humber \& Moss, 2005). Inter-rater reliability was very good and, as predicted, codes both diverged from the measure of parent-child relationship and converged with a separate measure of parent-child interaction quality,. Detailed profile review revealed nuanced areas of group and individual differences which may be specific to verbally-able school-age children. Results support the utility of the Relationship Development Assessment - Research version for clinical practice.
\end{abstract}

\title{
Keywords
}

Autism, joint attention, intersubjectivity, parent-child interaction, relatedness 


\section{Introduction}

Autism is a disorder characterised by atypical development in social communication and repetitive behaviour (APA, 2013). In the present study, we investigated how such impairments are manifest in the children's interactions and engagements with their caregivers. Recent developments in the field of autism treatment show an increasing move towards relationship-focussed interventions, which seek to remediate the pivotal features of autism through improving interactions with others, typically engaging with parents as facilitators of their children's development (Dawson et al., 2010; Gutstein, 2009; Green et al, 2010; Green et al., 2013; Kasari, Freeman \& Paparella, 2006; Mahoney \& Perales, 2003; 2005; Rogers et al., 2006; Wieder \& Greenspan, 2003). The growth in these interventions requires simultaneous evaluation of their efficacy. A crucial part of this endeavour is the development of outcome measures that demonstrate reliable and valid assessments of parent-child interaction (Lord et al., 2005). In addition, the endeavour to develop clinically-useful evaluation tools has consistently been highlighted as a priority area for the field of autism intervention (Cunningham, 2012; Kasari, 2002; Magiati et al., 2011). Creating more consistency in outcome measurement will allow clearer comparison between treatment studies and contribute to progress in the field of autism intervention research (Bölte \& Diehl, 2013).

\section{Autism and Relationship-based Intervention}

Increasingly, the influence of parent-child interaction on sociocognitive and linguistic development in children with autism is being recognised (Meltzoff, Kuhl, Movellan \& Sejnowski, 2009; Tomasello, Carpenter, Call, Behne \& Moll, 2005), with different interaction styles either promoting or hindering development (McArthur \& Adamson, 1996; Wan et al., 2013). For example, evidence suggests that parents of children with autism tend to spend more time controlling the child's behaviour (Kasari, Sigman, Mundy \& Yirmiya, 1988) and use more physical means to do so (Doussard-Roosevelt, Joe, Bazhenova \& Porges, 2003; Gulsrud, Jahromi \& Kasari, 2010). This trend may emerge in the infant years, with a recent study of infants at risk for autism showing that the infants elicited a more directive interactive style from parents (Wan et al., 2012). These patterns of interaction may contribute to an increasingly atypical developmental trajectory (Wan et al., 2012). For example, Wan and colleagues (2013) found that qualities of parent-child interaction in infants at risk for autism were associated with autism outcome at three years of age. 
This perspective on parent-child factors is complemented by the development of relationship-based interventions for autism, which target the child's interactions with adults or caregivers with the aim of enriching their developmental environment. A theoretical distinction can be drawn here between the concepts of relationship and relatedness: while the concept of relationship refers to enduring ways of relating to others (i.e. parent-child attachment style; siblings; friends) relatedness describes the moment-by-moment interactional style and engagement quality of interacting partners (see Beurkens, Hobson \& Hobson, 2013). The interactional processes promoted in interventions are those demonstrated through research to be integral to child development (Kasari, 2002). These can include promoting responsive parental teaching (i.e. Green et al., 2013; Mahoney \& Perales, 2003; 2005) or sensitive and responsive parental communication (i.e. Green et al., 2010); focussing on creating an affectively-warm, rich and positive social environment for the child-adult interaction (i.e. Denver Model: Rogers et al., 2006; Vismara \& Rogers, 2008); promoting guided engagements and experience-sharing between children with autism and their caregivers (i.e. RDI: Gutstein, 2009; Gutstein, Burgess and Montfort, 2007); or directly promoting contingent interaction and joint attention (i.e. DIR/Floortime: Solomon, Necheles, Ferch \& Bruckman, 2007, RDI: Gutstein, 2009). While these more recent approaches are less well supported than traditional behavioural approaches, empirical evidence for their efficacy is building (Odom et al, 2010; Rogers \& Vismara, 2008; Dawson et al., 2010). In light of recent suggestive findings, for example that parent-child synchrony was a strong mediating factor on the positive effects of a communication-focussed intervention (Aldred, Green, Emsley \& McConachie, 2012), and that parent-child interaction quality at baseline was a moderator of treatment gains as measured by the ADOS Severity Index (Author reference withheld for blind review), there is a pressing need to develop complementary measures of parent-child interaction.

\section{Measurement of Interactions}

With this focus on promoting intersubjective or interpersonal processes between parent and child, it is increasingly necessary to measure these dimensions reliably and validly. Traditional methodologies for assessing parent-child interaction have tended to focus on the individuals' separate contributions to the interaction, quantifying discrete acts (e.g. number of verbalisations, eye contact) rather than examining the 
An alternative means of judging interactional quality is the assignment of global ratings based on an extended interaction (Adamson et al, 2012). Currently a gold-standard tool for assessing social relatedness with an unfamiliar examiner in autism is the standardised measure, the Autism Diagnostic Observation Schedule (ADOS: Lord, Rutter, DiLavore \& Risi, 2001). Qualitative aspects of the interaction, such as the nature of social initiations and responses and the level of rapport between tester and child, are measured on a scale from 0-3. Users of the ADOS are required to undergo training, demonstrate an understanding of the coding criteria, and prevent rater drift through attendance at reliability meetings. With precautions such as these, qualitative judgements regarding an interaction can be made with sufficient reliability and validity (Gotham, Pickles \& Lord, 2009). A further tool, the ADOS-C, is currently under development, and is designed to provide a measure of change in autism symptomatology during relatively unstructured interactions with other people, including parents (Lord, Carr \& Grzadzinski, 2013). Adamson and colleagues (Adamson et al, 2012; Adamson, Bakeman \& Rogers, 2013) have recently used a similar approach for parent-child interactions in order to investigate the emergence and development of joint attention. Adamson et al (2012) applied global ratings to a video-taped observation, focussing on qualitative dimensions such as how attention is shared, fluency of the conversation and the level of parental scaffolding, using ratings from 1 to 7 . They found very high correspondence between 
global and state codings as well as very good inter-rater reliability. This methodology was also recently employed by Wan and colleagues, who made global ratings of caregiver sensitive responsiveness and dyadic intensity of engagement during caregiver-child interaction (Wan et al., 2012). The appeal of such global observational ratings is their greater practicability within a clinical setting, their ability to capture higher-order qualities of an interaction, and their efficiency in terms of coder time (Adamson et al, 2012; Angellilo et al, 2007; Beurkens et al., 2013; Lord, Carr \& Grzadzinski, 2013). Development of systematic, clinician-friendly, observational parent-child coding schemes is of key importance in investigating differences in parent-child interaction, informing treatment approaches and monitoring intervention outcomes (Adamson et al., 2013; Wan et al. 2012, 2013).

The current study Beurkens, Hobson and Hobson (2013) used video-taped interactions of 25 dyads consisting of a parent and their child with autism, coded using the Dyadic Coding Scales (DCS: Humber \& Moss, 2005), and found that the more severe a child's autism on the Autism Diagnostic Observation Schedule (ADOS: Lord et al, 2001), the poorer their interaction with their parents on qualities such as their shared communication, coordination of their actions and the ease of emotional expression between the pair. This study thereby supported the reliability and aspects of the validity of the DCS in assessing the quality of parent-child interaction. (Author reference withheld for blind review) then took a further sample of 18 dyads made up of a parent and their child with autism and replicated the findings of Beurkens and colleagues (2013), reporting that autism severity was closely related to interaction quality on the DCS. They also utilised two further coding schemes known as the Relationship Development Assessment (RDA) Coding Scales, which analysed the moment-by-moment quality of parent-child interaction, investigating two processes that they argue to be fundamental to the social impairments of autism. These processes are central to the therapeutic work undertaken throughout the family consultation programme of Relationship Development Intervention (RDI) and are used as the building blocks for a relationship incorporating 'guided participation' (see Gutstein, 2009; also Rogoff, 1990). The Relationship Development Assessment is a semi-structured evaluation of parent-child interaction utilised in RDI. In addition to more fine-grained analyses, the RDA is coded using the RDA Coding Scales. However, research is required to establish the reliability and validity of this approach. 
(Author reference withheld for blind review) used state or 'micro-level' coding to analyse the two processes in the RDA Coding Scales using the labour-intensive Observer XP coding system. The first process is the capacity of a dyad to regulate an interaction, collaborating to maintain a connected, fluid exchange. This collaboration or Interactive Regulation involves two aspects: how contingent each person's behaviour is on the other's (e.g. if the child bounces a ball towards the parent, will the parent catch and pass it back?) and the quality of elaboration each provide, by introducing variations that enhance the interaction (e.g. the parent then passing the ball backward over their head to generate more interest and fun). The second process is the capacity to engage affectively with the other, that is, the level and depth of Intersubjective Engagement - experiencesharing and affective contact that takes place between members of the dyad. Of relevance is whether the pair seem attuned to each others' emotional or intentional state (i.e. sharing a joke or sharing the intention to start a game 'Oh yeah, let's do it that way'), or whether the interactions are more directive or disengaged (e.g. 'Go stand there, catch the ball'). (Reference withheld for blind review) found that ratings of these processes corresponded to the global ratings, were sensitive to the severity of autism, were sensitive to change following treatment and could be evaluated with excellent inter-rater reliability.

As such, the RDA Coding Scales may represent a useful tool for use within the context of relationship-based intervention in order to guide interventions and evaluate outcomes. However the state-based coding used in (Author reference withheld for blind review) study required specialist Noldus Observer ${ }^{\circledR} \mathrm{XP}$ computer software. While this software is widely used in research settings, within a clinical setting it is generally impractical due to the expense and the time necessary to learn and effectively use this method. The current study focuses on improving the clinical utility of the coding schemes, by assigning global ratings rather than state-based ratings based on the interaction, thereby creating a clinical tool that is accessible, practicable and appropriate for the practicing clinician (Smart, 2006). We include a measure of shared attention between parent and child, based on the work of Lauren Adamson and colleagues (Adamson et al, 2004), who have recently investigated global ratings as a complement to state-based rating systems (Adamson et al., 2012; Adamson et al., 2013). We investigate whether this clinical tool, consisting of the parent-child interaction and three coding schemes with simplified rating systems demonstrates validity against other measures, 


\section{Hypotheses}

We predicted that the processes of attention (Coding Scheme 1), based on the work of Adamson and colleagues (2004), interactive regulation (Coding Scheme 2) and intersubjective engagement (Coding Scheme 3) would be compromised between children with autism and their parents as compared to children without autism and their parents, as these represent key interpersonal processes known to distinguish children with autism (Charman, 2003; Hobson, 2002/04; Mundy \& Sigman, 2006; Trevarthen \& Aitken, 2001; Wan et al., 2012). We also intended to examine the profile of scores across each of the three ratings in an exploratory fashion in order to investigate the strongest discriminating features. Given that the processes measured in the coding schemes are distinctive of autism, it was expected that these ratings would be poorer where autism severity was greater. We also anticipated that the coding schemes would show sensitivity to interactional features measured by a global measure of parent/child interaction quality. Finally because parent-child relationship quality appears to be affected by, but in other ways distinct from, interaction quality (Beurkens et al, 2013; Fogel, 2009), we expected that the quality of parent-child interaction would not be strongly related to parent-child relationship quality.

\section{Method}

The study was granted ethical approval by the Research Ethics Committee of the Health Service Executive South, in the south-east of Ireland. Children were recruited from the waiting list of an autism clinic in the Health Service Executive [HSE], through a private clinic and through mainstream primary schools in Ireland. Potential participants were identified and invited to participate by a clinician or special educational needs teacher and families gave consent before details were passed to the researcher. 


\section{Participants}

Inclusion criteria for the autism group were 1) cognitive ability in upper range of mild intellectual disability or higher (i.e. $(Q>65)$, 2) no comorbid psychiatric conditions (e.g. ADHD) and 3a) a clinical diagnosis of, or awaiting assessment for, an ASD ( $n=20)$. For children awaiting assessment, the research measures (below) formed part of their clinical assessments, in consultation with their clinical team and informed subsequent diagnoses. Children in the comparison group had to satisfy the first two conditions, as well as $3 \mathrm{~b}$ ) no clinical concern regarding the presence of an ASD and 4) presence of academic difficulties as evidenced by receipt of learning support hours at school $(n=20)$ (See Table 1). The comparison group was not intended to represent a homogenous diagnostic group, but to investigate whether the parent-child interaction coding schemes would differentiate between dyads of children with ASD and parent, from dyads of children without autism and parent (See Table 2 for learning difficulties of comparison group). Children who had difficulties with learning were selected in order to ensure close matching with the ASD group, who also tend to have learning difficulties (Baron-Cohen, 2008). This broad profile of comparison children allowed closer matching with the ASD group on verbal and nonverbal cognitive ability as well as chronological age, than would comparison with a typicallydeveloping group. In this respect, any difficulties among children with autism on measures of interest could be attributed to social-communication - rather than learning - difficulties.

\section{INSERT TABLE 1 AND TABLE 2 AROUND HERE}

All participants were administered the Autism Diagnostic Observation Schedule (ADOS: Lord et al., 2001) and the Social Responsiveness Scale (SRS: Constantino \& Gruber, 2005).

The Autism Diagnostic Observation Schedule (ADOS: Lord et al., 2001) is considered a gold-standard tool in the diagnosis of autism and autism spectrum disorders. The assessment consists of a $30-45$ minute interaction between the child and an examiner, using particular tasks such as reading a story from a book and creating a story using objects. Revised scoring procedures for the ADOS have been introduced since 2009 in order to calculate an autism severity metric, which quantifies severity of core autism symptomatology 
(Gotham, Pickles \& Lord, 2009). This ADOS-Severity Index was used for analyses in this study. The administrator and coder of the ADOS was trained to a standard of $80 \%$ reliability by a certified trainer.

The Social Responsiveness Scale (SRS: Constantino \& Gruber, 2005) is a 65-item parent report that assesses the domains of social awareness, social cognition, social communication, social motivation and autistic mannerisms. T-scores above 60 are indicative of the presence of an ASD. The SRS has been used widely in studies of autism (Aldridge, Gibbs, Schmidhofer \& Williams, 2012; Charman et al., 2007; Pine, Guyer, Goldwin, Towbin \& Leibenluft, 2008).

On the basis of these diagnostic measures, expert clinical judgement of the research team (which included a clinical psychologist and trainee clinical psychologist), and consultation with the diagnosing clinical team for cases undergoing an ASD assessment, participants were classified as either having an autism spectrum diagnosis $(n=20)$, or as non-ASD $(n=20)$. Only children who met DSM-IV criteria for Autism Spectrum Disorders were included in the ASD group. Where diagnostic measures conflicted, clinical judgement was used to establish diagnostic group: one child in the ASD group had an SRS score below 60, and 9 children in the comparison group had SRS scores above the diagnostic cut-off of 60 . The inclusion of these children in the respective groups was justified based on their clinical presentation, parent-reported concerns, and based on a caution that the SRS can show low specificity in clinical populations (Aldridge et al, 2012). An independent samples t-test confirmed that the ADOS severity score and the SRS Total Score were significantly different between the two groups, ADOS: $t(38)=-13.6, p<.001$; SRS: $t(38)=-6.4, p<.001$ (See Table 1 for descriptive data).

As well as chronological age and gender, groups were matched on verbal and non-verbal cognitive ability, as measured by the Kaufman Brief Intelligence Test - Second Edition (KBIT-2: Kaufman \& Kaufman, 2004). The KBIT-2 is a brief, individually-administered measure of the verbal and nonverbal intelligence of a wide range of children, adolescents, and adults which yields three scores: Verbal, Nonverbal and the overall score, known as the IQ Composite (Table 1). An independent samples t-test showed no significant difference between the two groups on Full Scale IQ, $t(38)=-.54, p=0.59$, Verbal IQ, $t(38)=-.99, p=0.32$ or Nonverbal IQ $t(38)=.08, p=0.94$.

Measures 


\section{INSERT TABLE 3 AROUND HERE}

Relationship Development Assessment - Research Version. In order to observe parent-child interaction, an abbreviated version of the Relationship Development Assessment (RDA), the observational assessment session used during RDI treatment, was administered and video-taped. This abbreviated assessment was developed with the supervision and input of the third author, a trainer expert in the use of this assessment tool. In this assessment, the parent and child are videotaped interacting over a standard set of activities to observe their degree of collaboration, joint attention and experience-sharing (Gutstein, 2000). Three specific tasks were chosen to provide an overview of the child and parent in different kinds of interaction - in collaborating over a shared task (e.g. joint construction), in a more fun, unstructured task (e.g. ball play) and in a task in which joint engagement would require greater structure (e.g. discovery box) (See Table 3). Parent and child were instructed to "Play with each other the way you would at home", the researcher left the room and returned briefly after 10-minute intervals to present the next activity.

Coding Schemes. The following three coding schemes were applied to the RDA-RV videotapes:

- Attention Engagement States (Adamson et al., 2004). This is a rating of joint attentional episodes between parent and child that has been adapted from a coding scheme by Adamson et al. (2004). In the current study, a simplified version was used to indicate how well children with autism shared attention with parents during interaction. In this study, this rating was assigned to 
INSERT TABLES 4, 5 AND 6 AROUND HERE

\section{Coding Procedures. Global ratings of Attention Engagement States and the RDA Coding Scales were assigned} based on the entire 30-minute RDA interaction, representing global judgements of the interactive processes at play rather than moment-by-moment ratings. The global ratings each described four levels of engagement, with better quality engagement indicated by higher scores (See Tables 4, 5 and 6). Raters made a judgement regarding how characteristic each level was of the dyad observed. Each level was judged to feature Usually (code 3), Often (code 2), Sometimes (code 1) or Not at All (code 0); these codes were multiplied by the values of the levels of engagement, and summed overall, to produce an overall rating between -8 and +8 (See Table 7). The coding schemes were presented and completed within an Excel spreadsheet which was formatted to automatically calculate the overall score. Coding of a 30-minute session typically took 45 minutes. [RDA Coding Scales and coding manuals are available from first author.] 
INSERT TABLE 7 AROUND HERE

Dyadic Coding Scale (Humber \& Moss, 2005): The Dyadic Coding Scale (DCS) was also applied to the videos to serve as a comparative measure of interaction quality. The DCS was developed to assess qualities of parentchild interaction in school-aged children, and focuses on aspects of secure attachment behaviour in typical development, as observed during a video-taped interaction. The domains measure the way in which the dyad negotiate their interaction, the affective qualities observed and a general rating of the relationship dynamic. A higher score on all domains indicates better interaction quality. For the current study, a DCS Total Score was also generated by adding the 9 scores between 1 and 7 , resulting in a score between 9 and 63 . We expected that the DCS Total Score would differ between groups, and correlate with standardised measures of autism severity (ADOS and SRS). We specifically predicted that the DCS Total Score would positively correlate with the Attention Engagement States and RDA Coding Scales ratings.

Coding Training and Reliability. Three raters (Raters 1, 2, 3) were blind to hypotheses, predictions and diagnoses, and coded all of the RDA-RV videos using either the DCS, AES or RDA Coding Scales. Rater 4 coded one-third (12) of the videos using each of these coding procedures. Reliability was established between Rater 4 and each of the other raters through discussion and joint coding on four videos and coding manuals were developed to guide subsequent independent coding. We calculated inter-rater reliability with intra-class correlations, applied to the overall scores, each of which had a possible range of -8 to +8 (Shrout $\&$ Fleiss, 1979). On the basis of the 12 videos, each rated independently by two separate coders, overall inter-rater reliability was excellent for Attention Engagement States (ICC $=.82)$, and on the RDA Coding Scales, inter-rater agreement was good for Interactive Regulation states (ICC $=.75)$ and excellent for Intersubjective Engagement (ICC=.82).

\section{Results}

INSERT TABLE 8 AROUND HERE 
Descriptive Analyses on Global Ratings

Descriptive data on the coding schemes can be seen in Table 9. Performance on Attention was relatively high (possible range -8 to 8 ), while dyads showed more difficulty with the capacity to regulate the interaction and engage affectively. To investigate the normality of the coding scheme data, skewness and kurtosis values and histograms were examined. A normal distribution was indicated, therefore parametric analyses were used throughout.

\section{INSERT TABLE 9 AROUND HERE}

\section{Discriminant Validity}

Overall Codes. This analysis was undertaken to examine whether the global rating Overall Codes could differentiate between the groups of children with and without autism. As can be seen in Figure 1, on the Overall Attention score, both groups showed similar levels of proficiency at sharing attention during interaction on the AES $\left(\mathrm{M}_{\mathrm{ASD}}=5.4, \mathrm{SD}_{\mathrm{ASD}}=1.3 ; \mathrm{M}_{\text {COMPARISON }}=5.8, \mathrm{SD}_{\text {COMPARISON }}=1.0, t(38)=1.08, p=.29\right)$. Within the RDA Coding Scales, on the Interactive Regulation (IR) Overall rating the ASD group showed significantly lower levels on the balance of contingency and elaboration within the dyad $\left(\mathrm{M}_{\mathrm{ASD}}=0.80, \mathrm{SD}_{\mathrm{ASD}}=2.66\right.$; $\mathrm{M}_{\text {COMPARISON }}=2.65, \mathrm{SD}_{\text {COMPARISON }}=2.68, t(38)=2.18, p=.035$. On the Intersubjective Engagement (IE) Overall rating, there was no group difference on levels of affective engagement between parent and child $\left(M_{A S D}=1.60\right.$, $\left.\mathrm{SD}_{\mathrm{ASD}}=2.18 ; \mathrm{M}_{\text {COMPARISON }}=2.85, \mathrm{SD}_{\text {COMPARISON }}=2.68, t(38)=1.61, p=.114\right)$. In summary, the IR Overall rating from the RDA-Coding Scales discriminated between groups and the IE and Attention Engagement Overall ratings were similar between the groups.

\section{INSERT FIGURE 1 AROUND HERE}

Profiles of Global Ratings. The profiles of scores within the coding schemes, rather than the Overall codes, were compared to examine whether there were different trends in performance between the groups, and how these trends related to measures of autism severity and parent-child interaction quality. Group comparisons were made where possible differences were evident. 
1. Attention Engagement States. Analysis of the AES codes revealed that the vast majority of dyads $(75 \%$, $\mathrm{n}=29$ ) were scored as 'mostly' in a state of coordinated joint attention, the highest level of engagement on this rating. However, on further analysis the ASD group showed significantly higher levels of Supported Joint Attention, where the partners directly prompt or scaffold each other to engage in the interaction, $\mathrm{M}_{\mathrm{ASD}}=1.80$, $\mathrm{SD}_{\mathrm{ASD}}=0.89 ; \mathrm{M}_{\text {COMPARISON }}=1.05, \mathrm{SD}_{\text {COMPARISON }}=0.22 ; t(38)=-3.6, p=.001$. (See Table 10$)$. This suggests that it was more difficult for the dyads with autism to engage spontaneously in shared exchanges.

2. RDA Coding Scales, Interactive Regulation. An independent samples t-test showed that the ASD group obtained significantly higher scores for the level of 'Contingency without Elaboration', $\mathrm{M}_{\mathrm{ASD}}=1.85, \mathrm{SD}_{\mathrm{ASD}}=$ $0.75 ; \mathrm{M}_{\text {COMPARISON }}=1.35, \mathrm{SD}_{\text {COMPARISON }}=0.67 ; t(38)=-2.23, p=.032$, indicating that they spent more time at this level of engagement than the comparison group (See Figure 2). This describes an interaction that is fixed and rigid, with few variations to increase the enjoyment and excitement for the interactants (Table 10).

\section{INSERT FIGURE 2 AROUND HERE}

3. RDA Coding Scales, Intersubjective Engagement. As Figure 3 shows, the ASD group were scored as showing significantly more 'Coordination of Actions' ( $M=1.9, S D=0.8)$ than the comparison group $(M=1.3, S D=0.8, t=-$ 2.38, $p=.022$ ), where partners engage by telling each other what to do, and attempt to control each other's actions, rather than engage with each other's intentions or feelings. Twenty-five percent of the ASD group were rated as 'mostly' at this level, whereas none of the comparison group obtained a code of 'mostly' on this rating, ( $p=.02$, Fisher's Exact test, one-tailed) - by contrast $55 \%$ of the comparison group were rated as 'mostly' engaged in Coordination of Intentions, where partners reference each other's intentions and movements so as to anticipate and share activity (See Table 10).

INSERT FIGURE 3 AROUND HERE 


\section{Convergent Validity}

This analysis was undertaken to examine whether the Overall global ratings and the profiles would cohere with measures of similar (DCS) and related constructs (ADOS and SRS), and thereby demonstrate convergent validity. Analyses were conducted both across the two groups and within the autism group.

Attention Engagement States Across Group Analyses. In line with our prediction, as Table 10 shows, Overall Attention ratings correlated significantly with the DCS Total, indicating that a better quality of parent-child interaction was associated with better coordination of attention. This was a moderate correlation in magnitude explaining $16 \%$ of the variance in the data. However, contrary to our prediction, the Attention ratings did not significantly correlate with standardised measures of autism severity: ADOS or SRS Total. As described above, Overall Attention ratings tended to be similar between groups, and did not pick up group differences in interaction, as both groups appeared to be proficient at coordinating attention to materials. However within the profiles the level of Supported Joint Attention correlated significantly with ADOS, $r(40)=0.44, p=.002$, and SRS, $r(40)=0.31, p=.025$, indicating that children with more impairment in socialcommunication and their parents found it more difficult to share attention spontaneously.

Attention Engagement States Within Group Analyses. Within the autism group, the Overall Attention score again did not correlate with ADOS or SRS, but the correlation between DCS Total and Attention remained significant, and moderate in magnitude, $r(20)=.45, p=.02$, one-tailed, indicating that among the children with autism, the capacity to share attention was associated with a better quality interaction.

RDA Coding Scales Across Group Analyses. In line with our prediction, Interactive Regulation (IR) and Intersubjective Engagement (IE) showed moderate correlation with the Dyadic Coding Scale (DCS) Total Score, explaining $31 \%$ and $39 \%$ of the variance respectively, indicating that the quality of parent-child interaction was 
RDA Coding Scales Within Group Analyses. Within the autism group, Interactive Regulation (IR) again correlated moderately with the Dyadic Coding Scale (DCS) Total Score, indicating that severity of autism was associated with the quality of the interaction, an association accounting for $25 \%$ of the variance. No significant correlation was found between IR and ADOS, or between IR and SRS Total, contrary to prediction. Within the autism group, the Intersubjective Engagement (IE) rating again showed a significant and strong correlation with the DCS Total Score, indicating that for children with autism, a poorer ability to engage on an affective level was associated with poorer interaction quality with the parent. This association accounted for $49 \%$ of the shared variance in scores. No correlation was found between IE and ADOS or SRS, contrary to prediction. This may have been due to the high-functioning level of the autism sample. Amongst the profiles the level of 'Lack of Contingency' was found to correlate strongly with ADOS, $r(20)=.55, p=.006$, one-tailed, indicating that children with more severe autism were less able to coordinate with their parent to engage in a reciprocal exchange. This difficulty with coordination and the establishment of mutually-rewarding play is vital clinical information - this level of specificity may be important to understand and support remediation of social interaction difficulties in verbally-fluent children with autism.

\section{INSERT TABLE 11 AROUND HERE}

\section{Divergent Validity}

This analysis was undertaken to examine whether the Overall codes would deviate from a measure of parentchild relationship, which is a theoretically distinct construct. Correlations were run between the seven Parent Child Relationship Inventory (PCRI) scales and the Overall codes. There was one exception, a significant 


\section{INSERT TABLE 12 AROUND HERE}

\section{Discussion}

The clinical tool in this study consisted of a semi-structured observational assessment (the Relationship Development Assessment - Research Version) and coding schemes adapted for ease of use in clinical settings, focussing on three interpersonal processes between parent and child: shared attentional focus, the capacity to co-regulate an interaction, and the capacity to share emotional experiences. Increasingly research on autism has focussed on parent-child interaction, measuring interactive qualities such as dyadic mutuality (Wan et al., 2013). However, there is a shortage of reliable and valid measures for assessing parent-child interaction in research settings (Lord et al., 2005) and fewer still that are appropriate to clinical settings (Merrell, 2001). The gap is particularly wide for measures appropriate for school-age, verbally-able children and their parents, for whom parent-infant interaction tasks are not applicable.

The current study found preliminary support for a clinical tool measuring parent-child relatedness. The inter-rater reliabilities of the coding schemes were sound, while evidence for validity provided a more nuanced picture. The Interactive Regulation Overall rating showed the strongest evidence of validity and reliability across the groups. Detailed profile reviews of the coding schemes provided information that is applicable to clinical practice, both in terms of assessment of parent-child interaction and in terms of guiding subsequent remedial intervention, while also giving direction to the further development of the coding schemes. The semi-structured interaction, the RDA-RV, provided a useful and easily-replicable context within which to observe parent-child dynamics. As Lord et al (2013) point out, observation and coding of naturalistic exchanges provides an important means of measuring subtle changes in core autism symptoms. 
Clinical Practice. Fine-grained analysis of the quantitative data revealed a number of discriminating features of interaction between children with autism and their parents that represent potential targets for intervention. For example on the Interactive Regulation rating, the information that parent-child dyads in which there is a child with autism spend greater amounts of time in rigid, unchanging patterns of interaction is consistent with previous research (Brigham et al., 2010; Doussard-Roosevelt et al., 2003; Wan et al., 2012). To illustrate, in one of the dyads in this study a mother and son played a game of 'thumb wrestling' repeatedly without variation at the boy's request, and this was followed by the mother becoming uninterested and slightly disengaged. Such forms of interaction may reduce the child's opportunities to learn flexible and dynamic ways of relating with others and with their environment. Therefore, this represents a key area for intervention, so as to increase the appeal and quality of parent-child interaction and thereby motivate the partners to engage with each other, facilitating the guided participation relationship so integral to development (Rogoff, 1990; Gutstein, 2001).

These practical, therapeutic ideas generated by the clinical tool suggests that it demonstrates 'treatment utility' - which is the degree to which an assessment contributes to treatment outcome (NelsonGray, 2003). In the time-limited work of a clinician, assessments that are meaningful for intervention, rather than those which are purely diagnostic, are essential: assessments should ideally be functional and lead to clinical application (Merrell, 2001). This clinical tool was relatively time-efficient, taking 45-minutes to code a 30-minute interaction, and requires less time and expertise to administer than an ADOS assessment. Furthermore, using the same measure to evidence change following treatment can be an important and powerful tool for use with families, and regular outcome monitoring can also help therapists to fit their interventions to the particular needs of a client (Nelson-Gray, 2003). The RDA-Coding Scales have been demonstrated to be sensitive to change following treatment in a previous study (Author reference withheld for blind review), thus they may operate well in this regard.

Because of the stigma generated by historical theories that autism was the consequence of neglectful or aloof parenting, interest in the relationship or interaction quality between parent and child has been neglected (Siller \& Sigman, 2002). Contemporary research has identified patterns of parent-child interaction that can either hinder or promote development (Adamson et al., 2010; Wan et al, 2012), and as such, 
interventions can now seek to empower the parent to engage with their child in sensitive and responsive ways so as to encourage their growth (Green et al., 2013; Kasari et al., 2010). The approach described in this paper helps to deepen our understanding of the facilitative aspects of parent-child interaction, which ultimately has implications for considering the nature of approaches to autism remediation.

Measure Development. Understanding which individual items are the strongest discriminators of group membership is an important consideration in a detailed examination of an assessment tool (Gillis et al., 2011). It may be the case that the Overall codes, generated by a weighted coding procedure, do not best reflect the differential performance of the dyads. One potential revision would be to refine the coding schemes to focus more closely on the areas with the greatest magnitude of group difference: this might follow a format like that used for the ADOS coding, where more salient codes relevant to diagnosis are included in the diagnostic algorithm. Procedures for establishing inter-rater reliability amongst clinicians should be outlined, which is common practice with other observational ratings (i.e. ADOS: Lord et al, 2001; Marschak Interaction Method Rating System, O’Connor, Ammen, Backman \& Hitchcock, 2001).

Limitations. One limitation relates to the functioning level of the sample: the participants with autism in this project were relatively high-functioning, as evidenced by a mean Full-Scale IQ score in the Average range, and by their verbal fluency, as evidenced by the administration of Module 3 of the ADOS to all participants. It is important to investigate in future research whether these coding schemes are equally applicable to younger and/or less verbally-able children. It may be the case that the interactional difficulties highlighted in this study are more specific to this higher-functioning group. Furthermore, for the purposes of validation of the coding schemes, this study had quite a small sample size, which limits the confidence of the conclusions. However, as a preliminary validation it suggests areas for refinement and replication.

Methodological Implications. Traditionally, observing features of the 'functioning unit' of parent and child has been considered 'elusive', and difficult to code (Adamson et al., 2012). This study highlighted the fact that with adequate training and the use of a coding manual, abstract concepts related to interpersonal engagement can be operationalised and measured reliably. This is particularly pertinent since measurement of outcome for 
The broad field of social skills interventions is yet in its infancy (Odom et al, 2010; Rogers \& Vismara, 2008). Relationship-based interventions are newer still, and as such, research on relevant outcome measures is an underdeveloped area of research (Kasari, 2002; Lord et al., 2005; Odom et al., 2010). This area of research remains at an exploratory stage, in which measure refinement is critical (Lord et al., 2005; Merrell, 2001). Results of this study are applicable in both research and clinical contexts, and contribute to the burgeoning field of investigating the influence and remediating effects of parent-child interaction on the development of children with autism.

\section{Acknowledgements}

We gratefully acknowledge XXXX which provided partial funding for the project to the third author. The project was completed by the first author to fulfil the requirements for the Doctorate in Clinical Psychology at XXXX. We thank the clinics who arranged recruitment and the families who participated. 


\section{References}

Adamson, L. B., Bakeman, R., \& Deckner, D. F. (2004). The development of symbol-infused joint engagement. Child Development, 75(4), 1171-87.

Adamson, L. B., Bakeman, R., Deckner, D. F., \& Nelson, P. B. (2012). Rating parent-child interactions: Joint engagement, communication dynamics, and shared topics in autism, down syndrome, and typical development. Journal of Autism and Developmental Disorders, 42(12), 2622-35.

Adamson, L. B., Bakeman, R., Deckner, D. F., \& Romski, M. (2009). Joint engagement and the emergence of language in children with autism and Down syndrome. Journal of Autism and Developmental Disorders, 39(1), 84-96.

Adamson, L.B., Bakeman, R. \& Rogers, D.L. (2013). Systematically observing changes in joint engagement during parent-child interactions. Paper presented at the International Meeting for Autism Research, San Sebastian, Spain. Abstract retrieved from https://imfar.confex.com/imfar/2013/webprogram/Paper13217.html.

Aldred, C., Green, J., Emsley, R., \& McConachie, H. (2012). Brief report: mediation of treatment effect in a communication intervention for pre-school children with autism. Journal of Autism and Developmental Disorders, 42(3), 447-54.

Aldridge, F. J., Gibbs, V. M., Schmidhofer, K., \& Williams, M. (2012). Investigating the clinical usefulness of the Social Responsiveness Scale (SRS) in a tertiary level, autism spectrum disorder specific assessment clinic. Journal of Autism and Developmental Disorders, 42(2), 294-300.

American Psychiatric Association (2013). Diagnostic and statistical manual of mental disorders. (5th ed.). Arlington, VA: American Psychiatric Publishing. 
Angellilo, C., Rogoff, B. \& Chavajay, P. (2007). Examining shared endeavours by abstracting video coding schemes with fidelity to cases. In R. Goldman, R.Pea, B.Barron \& S.J. Derry (Eds.). Video research in the learning sciences. (pp. 109-206). Mahway, NJ: Erlbaum.

Anthony, L.G., Anthony, B. J., \& Glanville, D.N., Naiman, D.Q., Waanders, C. \& Shaffer, S. (2005). The relationships between parenting stress, parenting behaviour and preschoolers ' social competence and behaviour problems in the classroom. Infant and Child Development, 154, 133-154.

Baron-Cohen, S. (2008). Autism and asperger Syndrome: The facts. Oxford; New York: Oxford University Press.

Beurkens, N., Hobson, J.A. \& Hobson, R.P. (2013). Autism severity and qualities of parent-child relations. Journal of Autism and Developmental Disorders, 43(1), 168-78.

Bolte, E.E. \& Diehl, J.J. (2013). Measurement tools and target symptoms/skills used to assess treatment responses for individuals with autism spectrum disorders. Journal of Autism and Developmental Disorders. Advance online publication. doi: 10.1007/s10803-013-1798-7

Brigham, N. B., Yoder, P. J., Jarzynka, M. A., \& Tapp, J. (2010). The sequential relationship between parent attentional cues and sustained attention to objects in young children with autism. Journal of Autism and Developmental Disorders, 40(2), 200-8.

Chalmers, D.J. (2006). Strong and Weak Emergence. In P. Clayton and P. Davies (Eds.). The re-emergence of emergence. (pp.244-256). Oxford University Press.

Collins, W. A., Maccoby, E. E., Steinberg, L., Hetherington, E. M., \& Bornstein, M. H. (2000). Contemporary research on parenting: The case for nature and nurture. American Psychologist, 55(2), 218-232. 
2

Constantino, J.N. \& Gruber, C. (2005). Manual: Social Responsiveness Scale. Los Angeles: Western Psychological Services.

Cunningham, A. (2012). Measuring change in social interaction skills of young children with autism. Journal of Autism and Developmental Disorders, 42(4), 593-605.

Dawson, G., Rogers, S., Munson, J., Smith, M., Winter, J., Greenson, J. Donaldson, A. \& Varley, J. (2010). Randomized, controlled trial of an intervention for toddlers with autism: The Early Start Denver Model. Pediatrics, 125(1), 17-23.

Doussard-Roosevelt, J. A, Joe, C. M., Bazhenova, O. V., \& Porges, S. W. (2003). Mother-child interaction in autistic and nonautistic children: characteristics of maternal approach behaviors and child social responses. Development and Psychopathology, 15(2), 277-95.

García-Pérez, R. M., Lee, A. \& Hobson, R. P. (2007). On intersubjective engagement in autism: a controlled study of nonverbal aspects of conversation. Journal of Autism and Developmental Disorders, 37(7), 1310-22.

Gerard, A. B. (1994). Parent Child Relationship Inventory: PCRI. Los Angeles: Western Psychological Services.

Gillis, J. M., Callahan, E. H., \& Romanczyk, R. G. (2011). Assessment of social behavior in children with autism: The development of the Behavioral Assessment of Social Interactions in young children. Research in Autism Spectrum Disorders, 5(1), 351-360.

Gotham, K., Pickles, A., \& Lord, C. (2009). Standardizing ADOS scores for a measure of severity in autism spectrum disorders. Journal of Autism and Developmental Disorders, 39, 693-705. 
Green, J., Charman, T., McConachie, H., Aldred, C., Slonims, V., Howlin, P., Le Couteur, A., et al. (2010). Parentmediated communication-focused treatment in children with autism (PACT): a randomised controlled trial. Lancet, 375(9732), 2152-60.

Green, J., Wan., M.W., Gulsrud, J., Holsgrave, S., McNally, J., Slonims, V., Elsabbagh, M., Charman, T., Pickles, A., Johnson, M., the BASIS team (2013). Intervention for infants at risk of developing autism: A case series. Journal of Autism and Developmental Disorders. Advance online publication. doi: $10.1007 / \mathrm{s} 10803-013-1797-8$

Gulsrud, A. C., Jahromi, L. B. \& Kasari, C. (2010). The co-regulation of emotions between mothers and their children with autism. Journal of Autism and Developmental Disorders, 40(2), 227-37.

Gutstein, S.E. (2000). Autism Aspergers: Solving the relationship puzzle - A new developmental program that opens the door to lifelong social and emotional growth. Arlington, TX: Future Horizons.

Gutstein, S. (2009). The RDI book; forging new pathways for Autism, Asperger's Syndrome and PDD with the Relationship Development Intervention programme. Houston, Texas, Connections Center Press.

Gutstein, S. E., Burgess, A. F., \& Montfort, K. (2007). Evaluation of the relationship development intervention program. Autism : The International Journal of Research and Practice, 11(5), 397-411.

Hobson, J.A., Tarver, L., Beurkens, N. \& Hobson, R.P. (under review). The relation between severity of autism and caregiver-child interaction: A study in the context of relationship-oriented Intervention. Manuscript Under Review.

Hobson, R.P. (2002/04). The Cradle of Thought, London; New York: Pan Macmillan / Oxford University Press. 
Humber, N., \& Moss, E. (2005). The relationship of preschool and early school age attachment to mother-child interaction. The American Journal of Orthopsychiatry, 75(1), 128-41.

Kasari, C. (2002). Assessing change in early intervention programs for children with autism. Journal of Autism and Developmental Disorders, 32(5), 447-461.

Kasari, C., Freeman, S., \& Paparella, T. (2006). Joint attention and symbolic play in young children with autism: a randomized controlled intervention study. Journal of Child Psychology and Psychiatry, and Allied Disciplines, 47(6), 611-20.

Kasari, C., Gulsrud, A.C., Wong, C., Kwon, S. \& Locke, J. (2010). Randomized controlled caregiver mediated joint engagement intervention for toddlers with autism. Journal of Autism and Developmental Disorders, 40(9), 1045-56.

Kasari, C., Sigman, M., Mundy, P., \& Yirmiya, N. (1988). Caregiver interactions with autistic children. Journal of Abnormal Child Psychology, 16(1), 45-56.

Kaufman, A.S. \& Kaufman, N.L. (2004). Kaufman Brief Intelligence Test, Second Edition (KBIT-2). AGS Publishing / Pearson Assessment.

Laranjo, J., Bernier, A., Meins, E., \& Carlson, S. M. (2010). Early manifestations of children's theory of mind: The roles of maternal mind-mindedness and infant security of attachment. Infancy, 15(3), 300-323.

Lord, C., Rutter, M., DiLavore, P. C., \& Risi, S. (2001). Autism Diagnostic Observation Schedule. Los Angeles: Western Psychological Services. 
Lord, C., Wagner, A., Rogers, S., Szatmari, P., Aman, M., Charman, T.,...Yoder, P. (2005). Challenges in evaluating psychosocial interventions for autistic spectrum disorders. Journal of Autism and Developmental Disorders, 35(6), 695-708.

Lord, C., Carr, T. \& Grzadzinski, R. (2013). Measuring emerging changes in social communication. Paper presented at the International Meeting for Autism Research, San Sebastian, Spain. Abstract retrieved from https://imfar.confex.com/imfar/2013/webprogram/Paper13309.html.

Magiati, I., Moss, J., Yates, R., Charman, T., \& Howlin, P. (2011). Is the Autism Treatment Evaluation Checklist a useful tool for monitoring progress in children with autism spectrum disorders? Journal of Intellectual Disability Research, 55(3), 302-12.

Mahoney, G., \& Perales, F. (2003). Using relationship-focused intervention to enhance the social emotional functioning of young children with autism spectrum disorders. Topics in Early Childhood Special Education, 23(2), 74-86.

Mahoney, G \& Perales, F. (2005). A comparison of the impact of relationship-focused intervention on young children with pervasive developmental disorders and other disabilities. Journal of Developmental and Behavioral Pediatrics, 26(2), 77-85.

McArthur, D., \& Adamson, L. B. (1996). Joint attention in preverbal children: autism and developmental language disorder. Journal of Autism and Developmental Disorders, 26(5), 481-96.

Meltzoff, A. N., Kuhl, P. K., Movellan, J., \& Sejnowski, T. J. (2009). Foundations for a new science of learning. Science, 325(5938), 284-8.

Merrell, K. (2001). Assessment of children's social skills: Recent developments, best practices, and new directions. Exceptionality, 9(1), 3-18. 
Mundy, P. \& Sigman, M. (2006). Joint attention, social competence and developmental psychopathology. In D. Cicchetti and D. Cohen (Eds.), Developmental psychopathology, second edition, volume one: Theory and methods, (pp. 293-332). Hoboken, N.J.: Wiley.

Nelson-Gray, R. O. (2003). Treatment utility of psychological assessment. Psychological Assessment, 15(4), 52131.

O'Connor, K. J., Ammen, S. A., Backman, T. L., \& Hitchcock, D. L. (2001). The Marschak Interaction Method Rating System. Unpublished instrument. California School of Professional Psychology, Alliant International University, Fresno, CA.

Odom, S. L., Boyd, B. A., Hall, L. J., \& Hume, K. (2010). Evaluation of comprehensive treatment models for individuals with autism spectrum disorders. Journal of Autism and Developmental Disorders, 40(4), $425-36$.

Osborne, L., McHugh, L., Saunders, J., \& Reed, P. (2008). The effect of parenting behaviors on subsequent child behavior problems in Autistic Spectrum Conditions. Research in Autism Spectrum Disorders, 2(2), 249263.

Rogers, S. J., Hayden, D., Hepburn, S., Charlifue-Smith, R., Hall, T., \& Hayes, A. (2006). Teaching young nonverbal children with autism useful speech: a pilot study of the Denver Model and PROMPT interventions. Journal of Autism and Developmental Disorders, 36(8), 1007-24.

Rogers, S. J., \& Vismara, L. A. (2008). Evidence-based comprehensive treatments for early autism. Journal of Clinical Child and Adolescent Psychology, 37(1), 8-38. 
Rogoff, B. (1990). Apprenticeship in Thinking - Cognitive Development in Social Context. New York; Oxford: Oxford University Press.

Shrout PE, Fleiss JL (1979). Intraclass correlations: uses in assessing rater reliability. Psychological Bulletin, 86, 420-428.

Siller, M., \& Sigman, M. (2002). The behaviors of parents of children with autism predict the subsequent development of their children's communication. Journal of Autism and Developmental Disorders, 32(2), 77-89.

Solomon, R., Necheles, J., Ferch, C., \& Bruckman, D. (2007). Pilot study of a parent training program for young children with autism: the PLAY Project Home Consultation program. Autism : The International Journal of Research and Practice, 11(3), 205-24.

Smart, A. (2006). A multi-dimensional model of clinical utility. International journal for quality in health care : journal of the International Society for Quality in Health Care / ISQua, 18(5), 377-82.

Tomasello, M., Carpenter, M., Call, J., Behne, T. \& Moll, H. (2005). Understanding and sharing intentions: The origins of cultural cognition. Behavioral and Brain Sciences, 28, 675-735.

Vismara, L.A. \& Rogers, S.J. (2008). The Early Start Denver Model: A Case Study of an Innovative Practice. Journal of Early Intervention, 31(1), 91-108.

Vygotsky, L. S. (1978). Mind in society: The development of higher psychological processes. In M. Cole, V. JohnSteiner, S. Scribner \& E. Souberman (Eds.). Cambridge, Mass; London: Harvard University Press.

Wan, M.W., Green, J., Elsabbagh, M., Johnson, M., Charman, T., Plummer, F., BASIS team (2012). Parent-infant interaction in infant siblings at risk of autism. Research in Developmental Disabilities, 33(3), 924-32. 
Wieder, S., \& Greenspan, S. I. (2003). Climbing the symbolic ladder in the DIR model through floor time/interactive play. Autism: The International Journal of Research and Practice, 7(4), 425-35. 


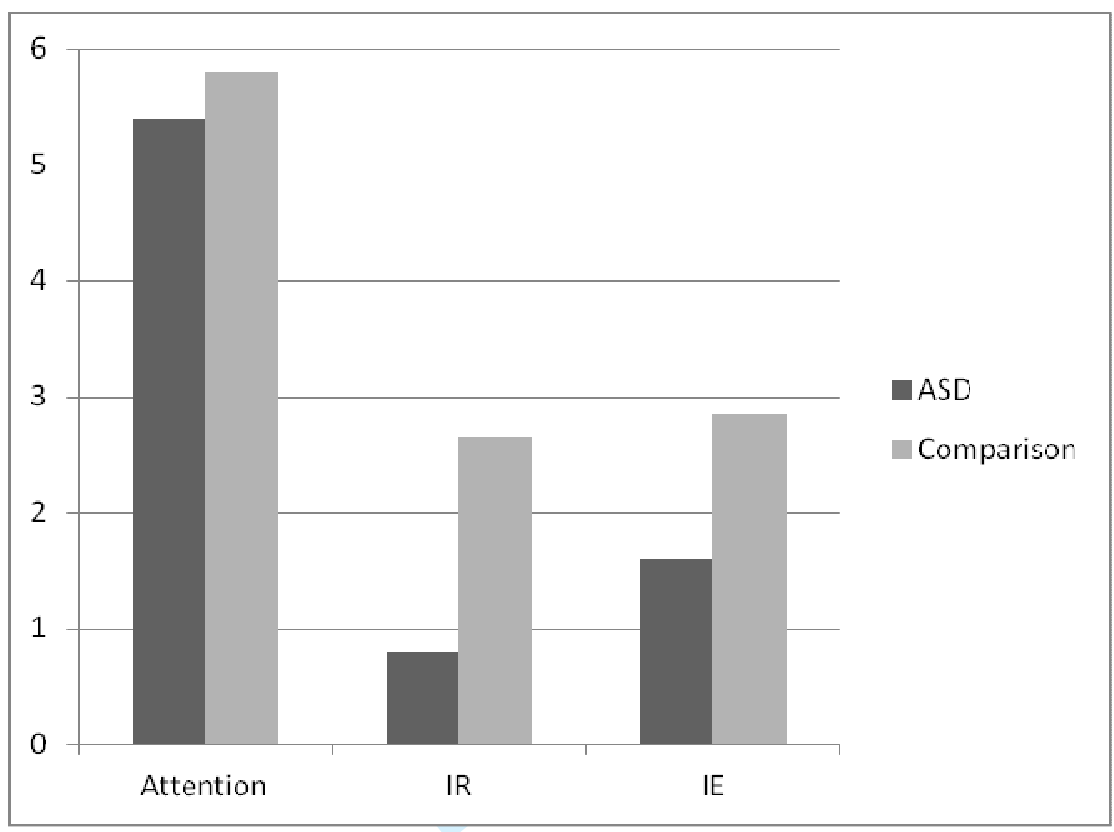

IR: Interactive Regulation; IE: Intersubjective Engagement

Figure 1. Mean group scores on Global Ratings Overall Codes. 




Figure 2. Profiles of IR Ratings By Group. 


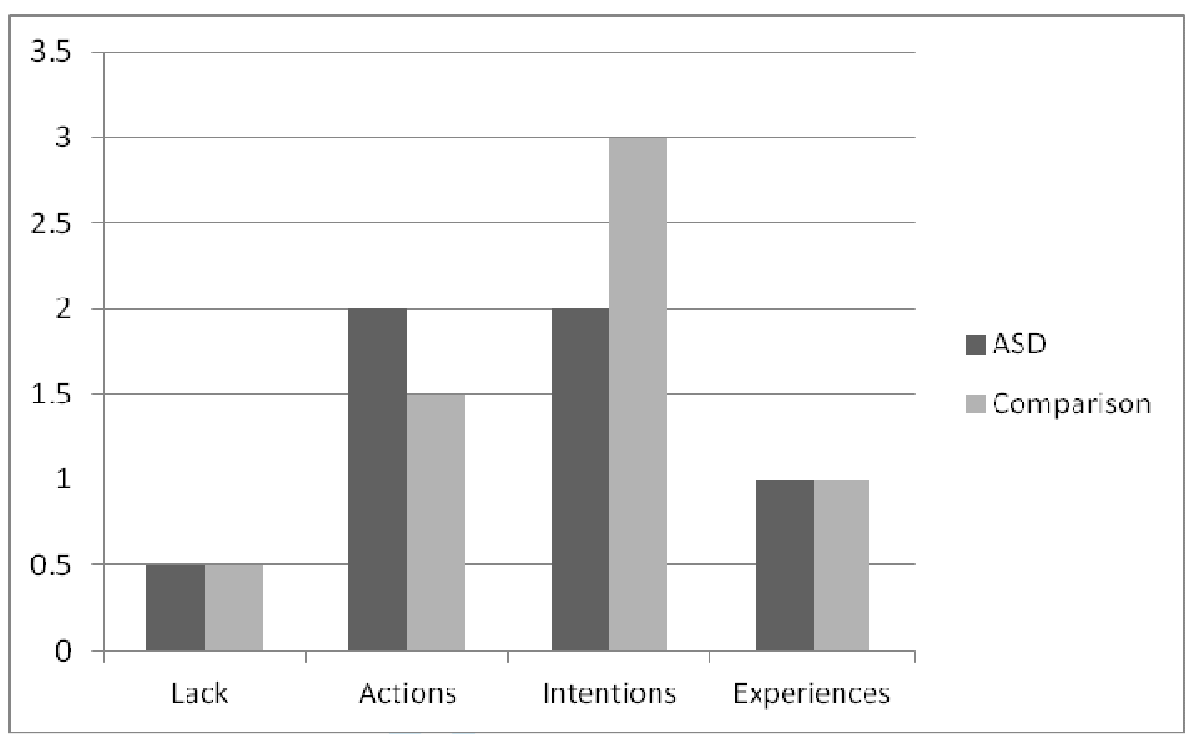

Figure 3. Median ratings on Levels of Intersubjective Engagement. 
Table 1. Descriptive Data for ASD and Comparison Groups.

\begin{tabular}{lll}
\hline & ASD group (n=20) & Comparison group (n=20) \\
& M (SD, Range) & M (SD, Range) \\
\hline Age & $9 ; 10(21$ months, 6;0-14;6) & $9 ; 6(11$ months, 7;4 - 11;0) \\
Gender & 16 male, 4 female & 16 male, 4 female \\
ADOS severity score & $7.1(1.7,4-10)$ & $1.3(0.6,1-3)$ \\
SRS Total score & $80.9(10.5,54-90)$ & $56.5(13.4,42-81)$ \\
Participating parent $(\mathrm{n})$ & Mother $(18)$, Father $(2)$ & Mother $(17)$, Father (3) \\
Ethnicity (n) & Caucasian (20) & Caucasian (18), Mixed race (2) \\
Verbal IQ & $92.2(13.7,63-117)$ & $87.3(17.3,58-117)$ \\
Nonverbal IQ & $92.9(17.5,59-126)$ & $93.3(16.3,58-124)$ \\
Full Scale IQ & $91.6(15.1,62-117)$ & $88.9(16.1,53-118)$ \\
\hline
\end{tabular}


Table 2. Diagnoses for Comparison group.

\begin{tabular}{ll}
\hline Diagnosis & $\mathrm{n}=20$ \\
\hline No diagnosis & 5 \\
Dyslexia & 9 \\
DAMP: Deficits in Attention, Motor control and Perception & 1 \\
Specific language impairment & 1 \\
Mild ID & 1 \\
Congenital deafness & 1 \\
Language impairment and dyspraxia & 2 \\
In receipt of additional supports at school (SNA, learning support, resource & 18 \\
hours) & \\
\hline Note: Diagnoses do not sum to 20 due to multiple diagnoses in some participants.
\end{tabular}


Table 3. Materials for RDA-RV

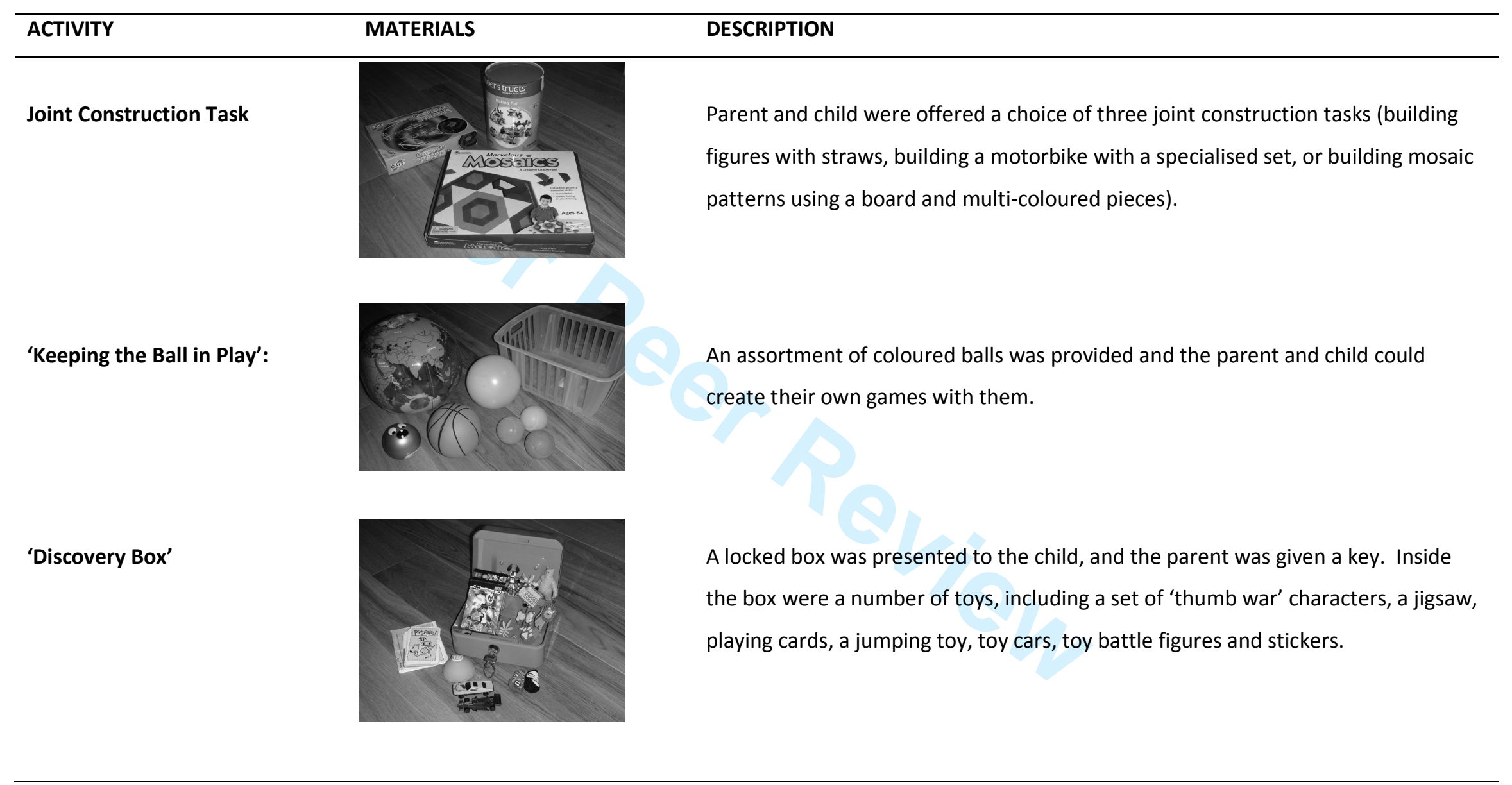


Table 4. Attention Engagement States (Adapted from Adamson et al, 2004)

\begin{tabular}{|c|c|c|c|}
\hline Level & Value & Description & Example \\
\hline$U$ & -2 & $\begin{array}{l}\text { The child is uninvolved with other } \\
\text { people, objects or events. }\end{array}$ & Child ignores all toys and adult's overtures. \\
\hline$S E$ & -1 & The child is engaged with objects only. & $\begin{array}{l}\text { Child constructs car while parent watches } \\
\text { silently. }\end{array}$ \\
\hline SJA & 1 & $\begin{array}{l}\text { The child and parent are engaged with } \\
\text { the same object, but the child is not } \\
\text { actively acknowledging the parent's } \\
\text { participation. }\end{array}$ & $\begin{array}{l}\text { Child makes patterns with mosaics while } \\
\text { parent comments or assists, but child does } \\
\text { not acknowledge what the parent says. }\end{array}$ \\
\hline CJA & 2 & $\begin{array}{l}\text { The child and parent are actively } \\
\text { engaged with the same object and } \\
\text { each other. }\end{array}$ & $\begin{array}{l}\text { Child asks parent to provide instructions in } \\
\text { construction task, and refers back to parent } \\
\text { for guidance. }\end{array}$ \\
\hline
\end{tabular}

Unengaged; SE: Solitary Engagement; SJA: Supported Joint Attention; CJA: Coordinated Joint Attention. 
Table 5. RDA Coding Scales - Interactive Regulation States.

\begin{tabular}{|c|c|c|c|}
\hline Level & Value & Description & Example \\
\hline Lack & -2 & $\begin{array}{l}\text { The dyad may be experiencing } \\
\text { disruption; absent joint engagement or } \\
\text { uncoordinated engagement. }\end{array}$ & $\begin{array}{l}\text { Child talks obsessively about a topic, } \\
\text { parent ignores and tries to introduce } \\
\text { an activity the child is not interested in. }\end{array}$ \\
\hline Static & -1 & $\begin{array}{l}\text { The dyad remain coordinated but at } \\
\text { the price of eliminating all variability } \\
\text { and elaboration of their joint activity. }\end{array}$ & $\begin{array}{l}\text { Parent and child throw a ball over and } \\
\text { back to each other with no chat or } \\
\text { variations. }\end{array}$ \\
\hline Unbalanced & 1 & $\begin{array}{l}\text { Contingency and elaboration are both } \\
\text { present but all contingent adjustments } \\
\text { and/or elaborations are made by one } \\
\text { member of the dyad. }\end{array}$ & $\begin{array}{l}\text { The parent tells the child to turn } \\
\text { around to elaborate a game of catch. }\end{array}$ \\
\hline Balanced & 2 & $\begin{array}{l}\text { There is a sense of mutual sensitivity } \\
\text { and responsiveness, as well as shared } \\
\text { goals and intentions. Both partners } \\
\text { add variations that enhance the } \\
\text { collaboration. }\end{array}$ & $\begin{array}{l}\text { Parent and child both introduce } \\
\text { variations into a game of catch. }\end{array}$ \\
\hline
\end{tabular}

Lack:Lack of Contingency; Static:Contingency without Elaboration; Unbalanced: Contingency without Elaboration; Balanced: Balanced Contingency and Elaboration. 
Table 6. RDA Coding Scales - Intersubjective Engagement States.

\begin{tabular}{|c|c|c|c|}
\hline Level & Value & Description & Example \\
\hline None & -2 & $\begin{array}{l}\text { No connection between the pair, or } \\
\text { only physical contact with no pattern } \\
\text { of interaction. }\end{array}$ & $\begin{array}{l}\text { Child holds on to parent but ignores her } \\
\text { introductions to games or toys and does not } \\
\text { answer her questions }\end{array}$ \\
\hline CA & -1 & $\begin{array}{l}\text { Instrumental communication: } \\
\text { partners influence each other for } \\
\text { discrete actions. }\end{array}$ & $\begin{array}{l}\text { Child asks for an object they want from the } \\
\text { parent, but there is no eye contact or } \\
\text { movement towards a planned joint activity }\end{array}$ \\
\hline $\mathrm{Cl}$ & 1 & $\begin{array}{l}\text { Partners anticipate each other's } \\
\text { actions and move towards joint goals }\end{array}$ & $\begin{array}{l}\text { Parent and child pass each other pieces to } \\
\text { complete a puzzle, discussing their strategy }\end{array}$ \\
\hline CE & 2 & $\begin{array}{l}\text { Partners show affective engagement, } \\
\text { show interest in the other's } \\
\text { reactions, and may share opinions or } \\
\text { memories, or use objects in a } \\
\text { symbolic manner. }\end{array}$ & $\begin{array}{l}\text { Child shows an object to their parent and recalls } \\
\text { a similar toy they played with on holiday }\end{array}$ \\
\hline
\end{tabular}

CA: Coordination of Actions; Cl: Coordination of Intentions; CE: Coordination of Experiences. 
Table 7. Examples of Scoring Procedure.

\begin{tabular}{llllllll}
\hline \multicolumn{7}{l}{ Interactive Regulation Rating } & \multicolumn{5}{l}{ Intersubjective Engagement Rating } \\
\hline Label & Value & Code & $\underline{\text { Sum }}$ & $\underline{\text { Label }}$ & $\underline{\text { Value }}$ & $\underline{\text { Code }}$ & $\underline{\text { Sum }}$ \\
Lack & -2 & Not at all $(0)$ & $(-2 \times 0)$ & None & -2 & Usually $(3)$ & $(-2 \times 3)$ \\
Static & -1 & Sometimes $(1)$ & $(-1 \times 1)$ & Actions & -1 & Sometimes $(1)$ & $(-1 \times 1)$ \\
Unbalanced & 1 & Sometimes $(1)$ & $(1 \times 1)$ & Intentions & 1 & Not at all $(0)$ & $(0 \times 1)$ \\
Balanced & 2 & Often (2) & $(2 \times 2)$ & Experiences & 2 & Not at all $(0)$ & $(0 \times 2)$ \\
\hline Total & & & $\mathbf{4}$ & & & $\mathbf{- 7}$ \\
\hline
\end{tabular}


Table 8. Objectives, Hypotheses, Predictions and Statistical Procedures

\begin{tabular}{|c|c|c|c|}
\hline Objective & Hypothesis & Prediction & Statistical Procedures \\
\hline Description & $\mathrm{n} / \mathrm{a}$ & $n / a$ & $\begin{array}{l}\text { Means, Standard Deviations and } \\
\text { tests of normality on each rating. }\end{array}$ \\
\hline Discriminant validity & $\begin{array}{l}\text { Children with autism and their parents have greater } \\
\text { difficulty in sharing attention, co-regulating an } \\
\text { interaction and with intersubjective engagement } \\
\text { relative to children without autism and their parents. }\end{array}$ & $\begin{array}{l}\text { Children with autism will show significantly lower } \\
\text { scores in parent-child relatedness on these coding } \\
\text { schemes. }\end{array}$ & $\begin{array}{l}\text { One-tailed t-tests on Overall } \\
\text { Codes. } \\
\text { Exploratory t-tests and Fisher's } \\
\text { Exact tests on profile patterns } \\
\text { within the ratings. }\end{array}$ \\
\hline Convergent validity & $\begin{array}{l}\text { The severity of autism will be associated with more } \\
\text { difficulty in parent-child interaction. The coding } \\
\text { schemes of shared attention, coregulation and } \\
\text { intersubjective engagement will show sensitivity to } \\
\text { interactional features also measured by a global } \\
\text { measure of parent/child interaction quality. }\end{array}$ & $\begin{array}{l}\text { The coding schemes will negatively correlate with } \\
\text { standardised measures of autism severity and will } \\
\text { positively correlate with an existing global measure } \\
\text { of parent-child interaction within and across the } \\
\text { groups. }\end{array}$ & $\begin{array}{l}\text { 1-tailed Pearson correlations } \\
\text { across both groups and within the } \\
\text { autism group. }\end{array}$ \\
\hline Divergent validity & $\begin{array}{l}\text { The three coding schemes of parent-child relatedness } \\
\text { measure a related but distinct construct to parent-child } \\
\text { relationship quality. }\end{array}$ & $\begin{array}{l}\text { There will be a weak relationship between the } \\
\text { coding schemes and a measure of parent/child } \\
\text { relationship. }\end{array}$ & 2-tailed Pearson correlations. \\
\hline
\end{tabular}


Table 9. Descriptive Analysis for Coding Schemes on Whole Sample, $n=40$.

\begin{tabular}{llll}
\hline & Attention & \multicolumn{2}{l}{ RDA Coding Scales } \\
\cline { 3 - 4 } & Engagement & Interactive Regulation & $\begin{array}{l}\text { Intersubjective } \\
\text { Engagement }\end{array}$ \\
\hline Range & 3 to 7 & -6 to 7 & -2 to 7 \\
M(SD) & $5.6(1.2)$ & $1.73(2.8)$ & $2.22(2.5)$ \\
Skewness & -.756 & -.181 & .397 \\
Kurtosis & -.089 & -.738 & -.738 \\
\hline
\end{tabular}


Table 10: Illustrative qualitative descriptions from coding schemes

\begin{tabular}{|c|c|}
\hline Coding Scheme and Code & Qualitative Description \\
\hline Attention Engagement States: & A mother and daughter play together. The child sings repetitive \\
\hline Supported Joint Engagement & $\begin{array}{l}\text { songs with her teddy bear, following her own interest and ignoring } \\
\text { the balls that the examiner has left for them to play with. The } \\
\text { mother draws her attention to a game of football she is setting up. } \\
\text { The child participates passively but tends to hug the mother } \\
\text { excessively after each goal and the mother has to continually } \\
\text { redirect the girl's attention to the game to avoid her talking } \\
\text { continuously or wandering around the room. }\end{array}$ \\
\hline Interactive Regulation: & A mother and son build a construction toy together. The mother \\
\hline Contingency without & sits attentively while the son independently follows the instructions \\
\hline Elaboration & $\begin{array}{l}\text { and builds the toy. While she is available to him and responsive to } \\
\text { his actions, she does not become actively involved as the child } \\
\text { resists her attempts to point out where different pieces should go } \\
\text { by moving the toy away from her. He occasionally points out what } \\
\text { he is doing for her but does not seek her input. His rigidity is } \\
\text { evident and the mother appears unhappy at being rejected. }\end{array}$ \\
\hline Intersubjective Engagement: & A mother and son play with a selection of balls. The child tells the \\
\hline Coordination of Actions & $\begin{array}{l}\text { parent to blow up a balloon for him. She does, and then uses the } \\
\text { balls to offer educational instruction on the solar system, and tells } \\
\text { him to watch what she is doing. The child moves about the room, } \\
\text { taking occasional interest. He tells the mother he wants to play } \\
\text { with another toy, but she tells him to put it away. }\end{array}$ \\
\hline
\end{tabular}


Table 11. Whole Sample and Within Autism Group Correlations of DCS, ADOS and SRS with Attention, Interactive Regulation and Intersubjective Engagement Overall Ratings.

\begin{tabular}{llll}
\hline & DCS Total & ADOS & SRS Total \\
\hline Attention Whole sample $\mathrm{n}=40$ & $0.41^{* *}$ & -0.08 & -0.06 \\
Attention ASD group $\mathrm{n}=20$ & $0.45^{*}$ & 0.26 & 0.21 \\
IR Whole Sample $\mathrm{n}=40$ & $0.56^{* *}$ & $-0.36^{*}$ & $-0.44^{* *}$ \\
IR ASD group $\mathrm{n}=20$ & $.50^{*}$ & -.22 & -.22 \\
IE Whole Sample $\mathrm{n}=40$ & $0.63^{* *}$ & $-0.28^{*}$ & $-0.32^{*}$ \\
IE ASD group $\mathrm{n}=20$ & $.70^{* *}$ & -.19 & -.04
\end{tabular}

** $p<0.01, * p<0.05$, one tailed. 
Table 12. Correlations of PCRI with Global Ratings.

\begin{tabular}{llllllll}
\hline & Supp & Satis & Inv & Comm & Lim & Aut & Role \\
\hline AES & .035 & -.169 & -.098 & .022 & -.013 & .061 & -.059 \\
$I R$ & .23 & .008 & -.064 & .224 & .161 & .244 & $.397^{*}$ \\
$I E$ & .012 & -.02 & -.127 & .121 & .168 & .036 & .218 \\
\hline \multirow{2}{*}{,$p<0.05$, one-tailed. } & & & & &
\end{tabular}

Supp: Support; Satis: Satisfaction; Inv: Involvement; Comm: Communication; Lim: Limit Setting; Aut: Autonomy; Role: Role Orientation 